\title{
Highly active P25@Pd/C nanocomposite for the degradation of Naphthol Blue Black with visible light
}

\author{
Balu Krishnakumar a, *, Santosh Kumar a , João M. Gil b, V. Pandiyan c, António Aguiar a , \\ Abilio J.F. N. Sobral ${ }^{\text {a, }}{ }^{* *}$ \\ a Department of Chemistry, University of Coimbra, 3004-535 Coimbra, Portugal

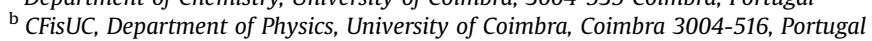 \\ ${ }^{c}$ Department of Physics, Nehru Memorial College (Autonomous), Puthanampatti 621007, Tamil Nadu, India
}

\section{A R T I C L E I N F O}

\section{Article history:}

Received 10 July 2017

Received in revised form

28 September 2017

Accepted 29 September 2017

Available online 30 September 2017

\section{Keywords:}

P25

$\mathrm{Pd} / \mathrm{C}$

NBB

Visible light

\begin{abstract}
A B S T R A C T
$\mathrm{TiO}_{2}$-P25 supported Pd/C (P25@Pd/C) composite was prepared by the solid state dispersion method. The prepared composite was characterized by XRD, Raman, PL, SEM and DRS measurements. The photocatalytic activity of the composite was tested towards Naphthol Blue Black (NBB) azo dye degradation under visible light. The photocatalytic activity of P25 was highly influenced by Pd/C. Almost complete degradation was achieved with P25@Pd/C in 120 min, and found to be more efficient when compared with pristine Degussa-P25. The composite was reused in four cycles without loss of activity. A mechanism was proposed for NBB degradation by P25@Pd/C composite under visible light.
\end{abstract}

๑) 2017 Elsevier B.V. All rights reserved.

\section{Introduction}

Photocatalyst is of high interest due to its applicability on environmental pollution correction. Titanium dioxide $\left(\mathrm{TiO}_{2}\right)$ is well known as a photocatalyst for the removal of environmental contaminants [1-3]. With increasing concerns about environmental pollution, environmental cleaning has attracted a great deal of attention owing to the increase in the level of environmental pollution worldwide. Photocatalysis on photocatalyst surfaces is of current vital interest with respect to both fundamental understanding and potential practical utilization. It is well known that degradation of organic compounds to $\mathrm{CO}_{2}$ and $\mathrm{H}_{2} \mathrm{O}$ can be accomplished using the ultraviolet (UV) or visible irradiation with photocatalsyts [3-6]. During the photocatalytic degradation process, UV or visible irradiation of a photocatalyst excites electrons from the valence band (VB) to the conduction band ( $\mathrm{CB}$ ) and leaves the holes in $\mathrm{VB}$. $\mathrm{TiO}_{2}$, a semiconducting material, has been extensively used on environmental applications, self-cleaning,

\footnotetext{
* Corresponding author.

** Corresponding author.

E-mail addresses: chemkrishna2006@yahoo.co.in (B. Krishnakumar), asobral@ci. uc.pt (A.J.F.N. Sobral).
}

deodorizing and sterilizing applications owing to its abundant resource, excellent photocatalytic performance [1-3]. However, the activity of $\mathrm{TiO}_{2}$ could be limited because of its fast electron-hole recombination. In order to enhance its efficiency many efforts have been made so far [7-10]. Recently, Rongrong Ma et al. [11], reported magnetic activated carbon-supported $\mathrm{F}$ and $\mathrm{N}$ co-doped $\mathrm{TiO}_{2}$ for salicylic acid degradation. The activated carbon is one of the good materials to enhance the photocatytic activity of the semiconductor. Also, Chuang Wang et al. [12], reported carbon foam-loaded nano- $\mathrm{TiO}_{2}$ photocatalyst and its degradation on methyl orange. Carbon foam (CF) is a light three-dimensional reticular material consisting of plenty of pores and interconnected hole walls with super adsorption capability. Methyl orange was taken as a model pollutant and the degradation efficiency of nano- $\mathrm{TiO}_{2} / \mathrm{CF}$ was evaluated under UV light, and nano- $\mathrm{TiO}_{2} / \mathrm{CF}$ photocatalyst exhibited the most desired efficiency in the degradation of methyl orange solution, reaching up to $83-87 \%$.

Now the research is focused on co-doping two kinds of elements into semiconducting materials as this three component system resulted in increased photocatalytic activity. Velmurugan et al. [13], have reported that co-doping of 'Pd' metal into sulphated titania causes the synergistic effect on the solar photodegradation of Reactive Red 120 (RR 120) dye. Initially $\mathrm{TiO}_{2}-\mathrm{SO}_{4}^{2-}$ was prepared by a sol-gel method and later 'Pd' was deposited on the surface of 
sulphated titania through photo-deposition method. The synergism between $\mathrm{SO}_{4}^{2-}$ and 'Pd' metal results enhance the photocatalytic activity. Pd-co-doped $\mathrm{TiO}_{2}-\mathrm{SO}_{4}^{2-}$ was found to be reusable catalyst. Many studies reveal that presence of Pd and activated carbon based materials enhanced the efficiency of semiconductors [14-20]. The electro-oxidation of methanol was studied in alkaline solution on Pd nanoparticles supported on carbon black (XC-72R, C) and $\mathrm{TiO}_{2} / \mathrm{C}$ composite reported by Estudillo-Wong et al., [19]. In the present work, from the above discussion, 'Pd' and activated carbon co-modification of semiconductor expected to be a good photocatlyst. Degussa $\mathrm{TiO}_{2}-\mathrm{P} 25$ was modified with $\mathrm{Pd} / \mathrm{C}$ using simple solid state dispersion method. Degussa $\mathrm{TiO}_{2}-\mathrm{P} 25$ (80\% anatase; $20 \%$ rutile) is a well-known and widely investigated photocatalyst [2]. The prepared composite catalyst was effectively utilized for degradation of toxic azo dye NBB under visible light.

\section{Experimental section}

\subsection{Materials and measurements}

Naphthol Blue Black (NBB) azo dye and Pd/C (10 wt\% of 'Pd') were purchased from Aldrich and used as received. The structure of the dye and its absorption maxima are given in Fig. 1. A gift sample of $\mathrm{TiO}_{2}-\mathrm{P} 25$ was obtained from Degussa (Germany). It is an 80:20 mixture of anatase and rutile. It has a particle size of $30 \mathrm{~nm}$ and BET specific area $50 \mathrm{~m}^{2} \mathrm{~g}^{-1}$. Powder X-ray diffraction (PXRD) patterns of solids were recorded using a Bruker D8 Advance diffractometer, equipped with a $3 \mathrm{~kW}$ generator, using $\mathrm{Cu} \mathrm{K} \alpha$ radiation $(\lambda=0.15418 \mathrm{~nm}) \mathrm{X}$-ray tube and a Lynx Eye Detector. Data were collected in Bragg-Brentano geometry with a fixed $0.3^{\circ}$ divergence slit. Scanning electron microscope (SEM) images were taken in Tescan Vega3 SBH scanning electron microscope. Images were collected using a secondary electron detector. DRS-UV-Vis absorption spectra of solid samples were obtained from a Shimadzu UV-2450 double-beam spectrometer with an integrating sphere over the range $200-800 \mathrm{~nm}$. The absorption spectra were recorded using an OCEAN OPTICS USB 4000 UV spectrometer.

\subsection{Preparation of $P 25 @ P d / C$}

Exactly $500 \mathrm{mg}$ of P25 dispersed in $25 \mathrm{~mL}$ of 2-propanol, and appropriate amount of $\mathrm{Pd} / \mathrm{C}$ was dispersed in $10 \mathrm{~mL}$ of 2-propanol followed by 2 min sonication. The Pd/C depression was mixed with P25 dispersion under stirring and was continued to $12-15 \mathrm{~h}$. The formed P25@Pd/C composite was filtered, air-dried at $115^{\circ} \mathrm{C}$ for $5 \mathrm{~h}$ in a hot-air oven. This catalyst contains 9 wt\% of Pd/C on P25, and $9 \mathrm{wt} \%$ was reported to be optimum loading of activated carbon on $\mathrm{ZnO}$ for the degradation of Direct Blue 53 under direct solar light [21].

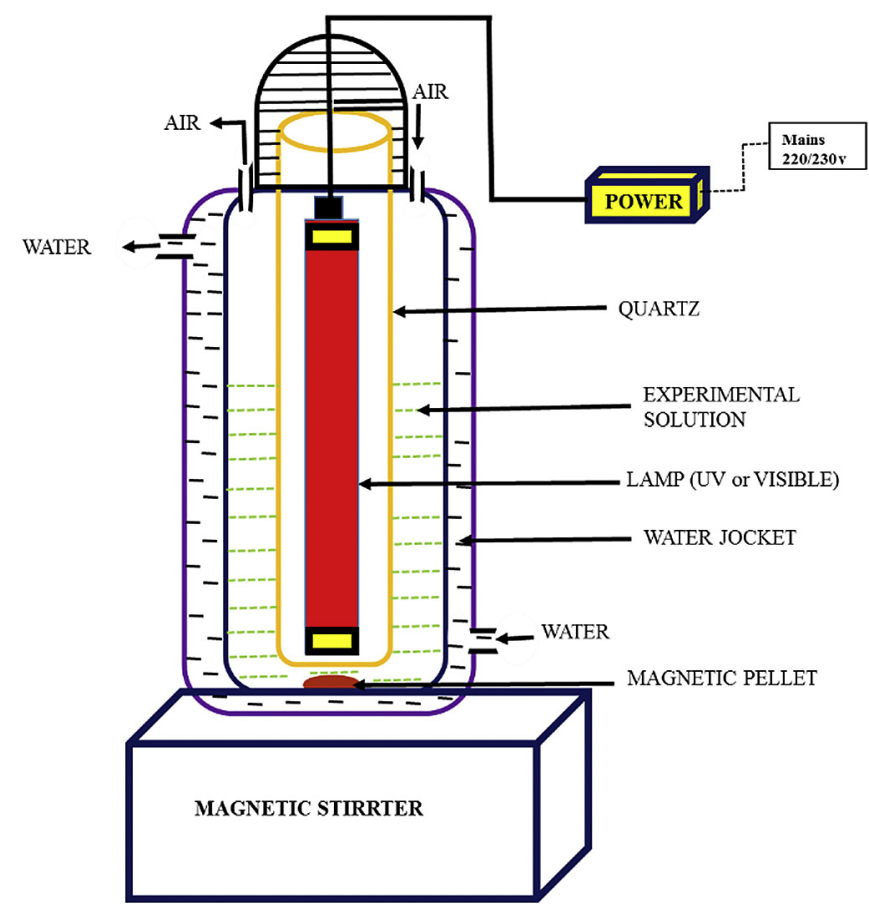

Fig. 2. Schematic diagram of immersion type photoreactor.

\subsection{Photodegradation experiments}

Photocatalytic activities of the as-obtained photocatalysts were evaluated by the degradation of NBB azo dye using visible light under immersion type photoreactor. Heber immersion type photoreactor model HP-SLJV16254, whose schematic diagram is shown in Fig. 2. This model consisted of a double walled immersion well made of a quartz reactor of $175 \mathrm{~cm}^{3}$ capacity. A small diameter inlet tube extended down the annular space to ensure flow of the coolant from bottom of well upwards to outlet. In the centre of cylindrical reactor, the lamps (UV or visible) used for light source was placed inside the quartz tube. For present experiments visible lamp was used ( $150 \mathrm{~W}$, Tungsten visible lamp). The reaction vessel had an arm at the top for gas purging. The temperature of the experimental solution was maintained at $25^{\circ} \mathrm{C}$ by circulating water during the experiments. The above set-up was placed in the magnetic stirrer for complete mixing of the catalyst. In each experiment, the reaction suspension consisting on $10 \mathrm{mg}$ of the photocatalyst in $100 \mathrm{~mL}$ of NBB solution (10 ppm), was magnetically stirred in the dark for 30 min to ensure the adsorption/ desorption equilibrium between the photocatalyst particles and NBB dye. Then the suspension was exposed to the visible

\begin{tabular}{|l|l|l|}
\hline Name of the dye & Structure of the dye & $\begin{array}{l}\text { Absorption } \\
\text { maxima (nm) }\end{array}$ \\
\hline $\begin{array}{l}\text { Naphthol Blue } \\
\text { Black }\end{array}$ & $\mid$
\end{tabular}

Fig. 1. The structure of the NBB dye and it's absorption maxima. 
irradiation, and aliquots $(4 \mathrm{~mL})$ were sampled at given time intervals and centrifuged to remove photocatalyst particles. The supernatants were analyzed by recording the absorbance variations of an absorption band $(615 \mathrm{~nm})$ in the UV-Visible spectrum of NBB.

\section{Results and discussion}

\subsection{Characterization of P25@Pd/C}

The prepared catalyst P25@Pd/C was characterized by X-ray diffraction (XRD), Raman spectra, photoluminescence spectra (PL), diffuse reflectance spectroscopy (DRS)) and scanning electron microscopy (SEM) images, as well as the bare $\mathrm{TiO}_{2}-\mathrm{P} 25$ for comparison. Fig. 3 shows the XRD patterns of $\mathrm{TiO}_{2}-\mathrm{P} 25$ and P25@Pd/C composite. $\mathrm{TiO}_{2}$-P25 is composed of both anatase (JCPDS card no. 21-1272) and rutile (JCPDS card no. 21-1276) phases of $\mathrm{TiO}_{2}$ [22] (Fig. 3a). The modification of P25 with $\mathrm{Pd} / \mathrm{C}$ does not change the phase composition, although the broad peak between degrees 23 and 28 is observed in Fig. 3b, suggesting that the presence of carbon a typical amorphous structure [23]. No diffraction peaks of individual Pd particles could be observed because of its low loading or may be small size. The as-prepared P25@Pd/C and bare P25 were further characterized by Raman scattering spectroscopy (Fig. 4). In the curve of $\mathrm{TiO}_{2}-\mathrm{P} 25$, the Raman scattering peaks at 154.0, 393.9, 516.3 and $632.4 \mathrm{~cm}^{-1}$ can be associated with $\operatorname{Eg}(1), \operatorname{Bg}(1), \operatorname{Ag}(1)+\operatorname{Bg}(2)$ and $\operatorname{Eg}(3)$ modes of
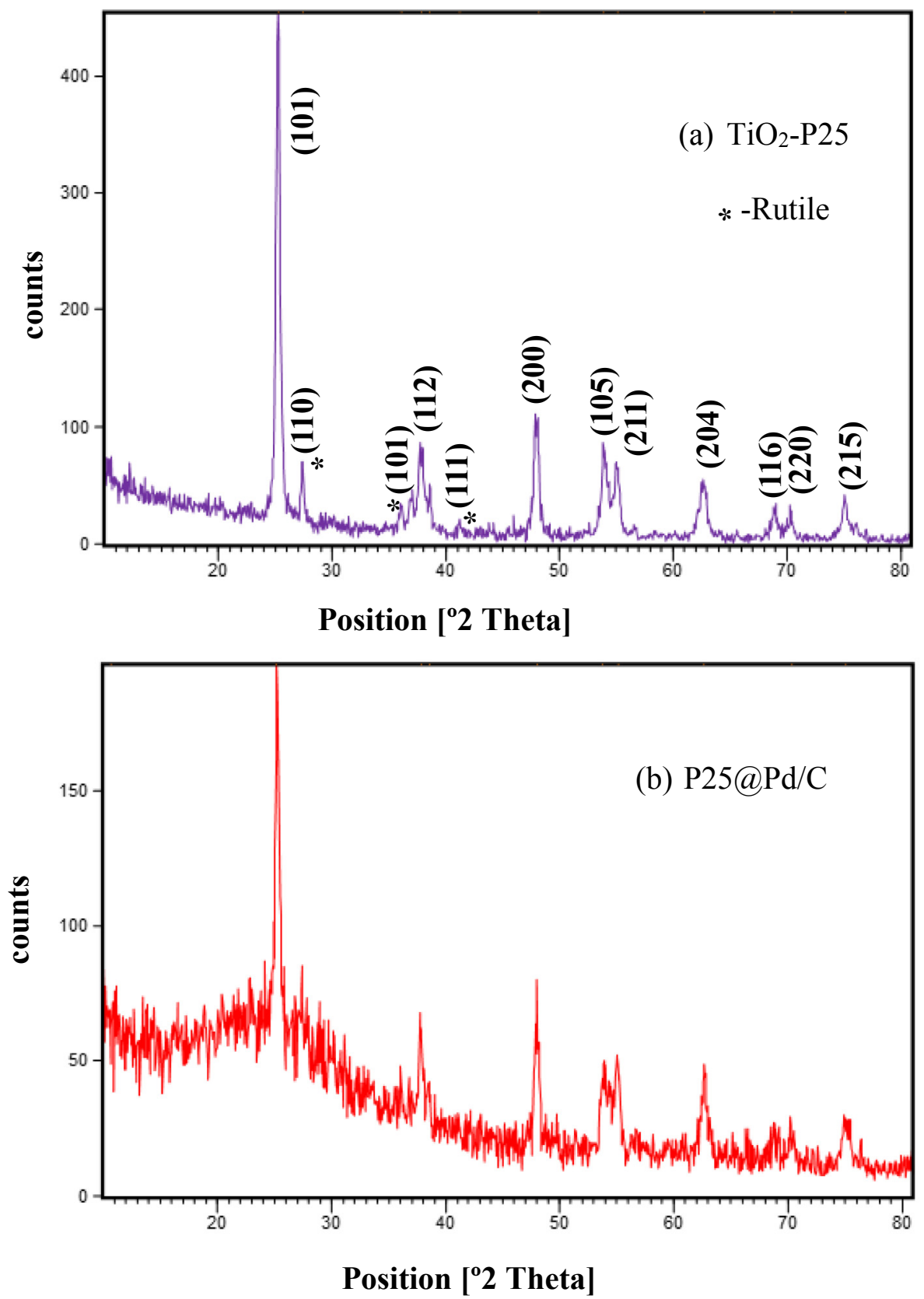

Fig. 3. XRD patterns of a) $\mathrm{TiO}_{2}-\mathrm{P} 25$ and b) $\mathrm{P} 25 @ \mathrm{Pd} / \mathrm{C}$. 

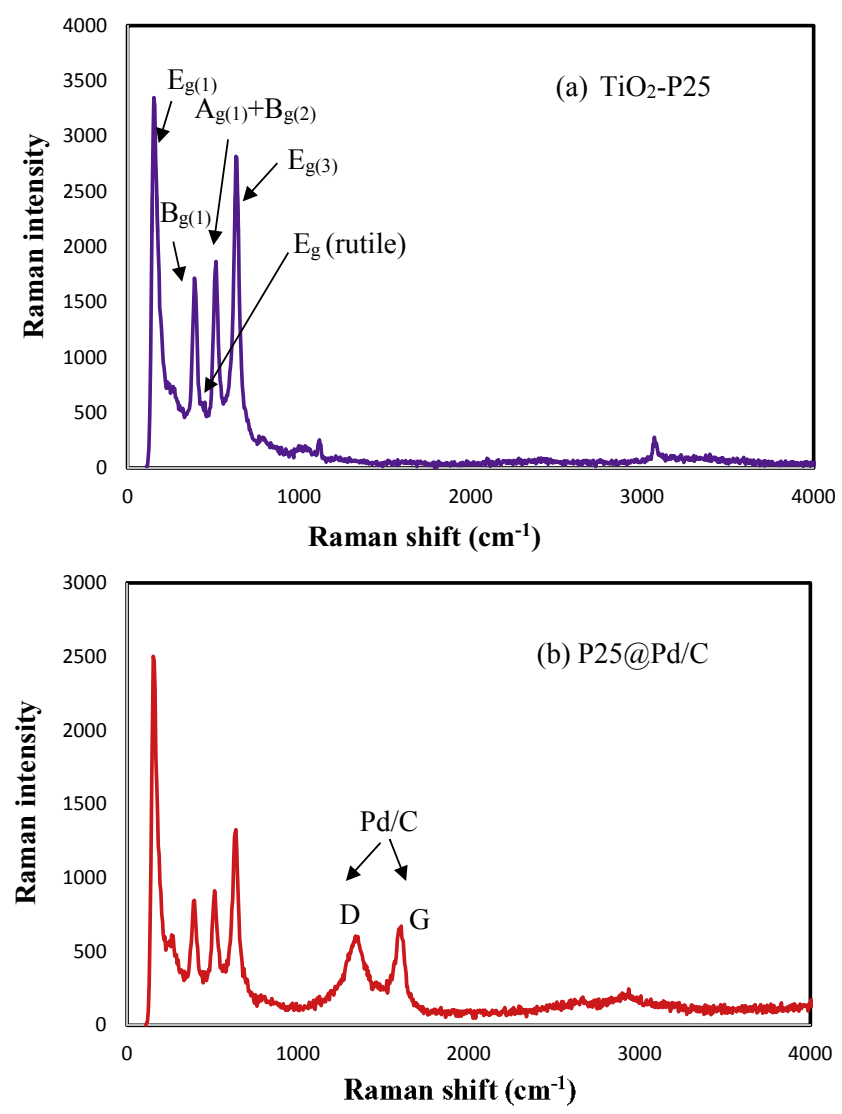

Fig. 4. Raman spectra of a) $\mathrm{TiO}_{2}-\mathrm{P} 25$ and b) $\mathrm{P} 25 @ \mathrm{Pd} / \mathrm{C}$.

anatase $\mathrm{TiO}_{2}$, respectively (Fig. 4a) [22]. In addition, the Raman phonon vibrational mode of rutile $\mathrm{TiO}_{2}$ at $483.1 \mathrm{~cm}^{-1}$ correspond Eg, since $\mathrm{TiO}_{2}-\mathrm{P} 25$ has both anatase and rutile phase. Due to the coverage of Pd/C network on the surface of P25, the intensities of anatase and rutile peaks of $\mathrm{TiO}_{2}-\mathrm{P} 25$ decrease in the curve of P25@Pd/C (Fig. 4b). Furthermore, the characteristic G-band and Dband peaks of carbon materials obviously appear at 1599.8 and $1347.3 \mathrm{~cm}^{-1}$, respectively (Fig. 4b) which confirms the presence of $\mathrm{Pd} / \mathrm{C}$ in P25@Pd/C. The morphology of $\mathrm{TiO}_{2}-\mathrm{P} 25$ and P25@Pd/C was

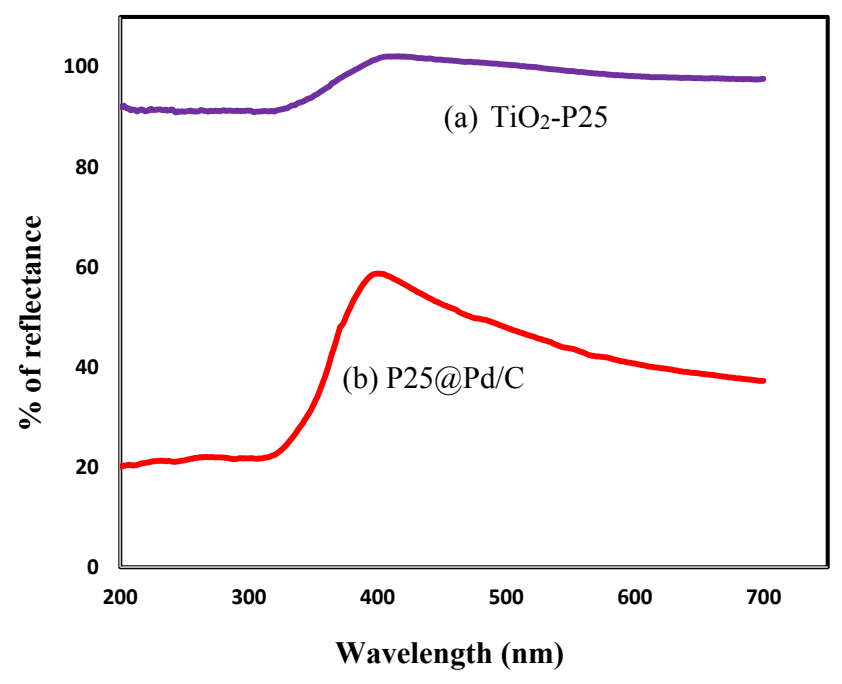

Fig. 6. DRS of a) $\mathrm{TiO}_{2}-\mathrm{P} 25$ and b) $\mathrm{P} 25 @ \mathrm{Pd} / \mathrm{C}$.

observed by SEM, and as given in Fig. 5. We could see the separated particles in $\mathrm{TiO}_{2}-\mathrm{P} 25$ (Fig. 5a), whereas P25@Pd/C, the particles are agglomerated and $\mathrm{Pd} / \mathrm{C}$ are uniformly distributed on the surface of $\mathrm{TiO}_{2}$-P25 (Fig. 5b), indicated by arrow marks.

The diffuse reflectance spectra (DRS) of $\mathrm{TiO}_{2}-\mathrm{P} 25$ and P25@Pd/C are depicted in Fig. 6a and b, respectively. P25@Pd/C has higher absorption than bare $\mathrm{TiO}_{2}-\mathrm{P} 25$ in both UV and visible region. Although there was no absorption in visible region for $\mathrm{TiO}_{2}-\mathrm{P} 25$ (Fig. 6a), however, P25@Pd/C has strong absorption in visible region (Fig. 6b), this may be due to presence of Pd/C on the surface of P25. Furthermore, the band gap value is obtained from the plot of the modified Kubelka-Munk function $(F(R) E)^{1 / 2}$ versus the energy of the absorbed light $\mathrm{E}$ [24]. The band gap energies of $\mathrm{TiO}_{2}-\mathrm{P} 25$ and P25@Pd/C are found to be 3.23 and $3.13 \mathrm{eV}$ respectively (Fig. 7). Photoluminescence spectra of $\mathrm{TiO}_{2}-\mathrm{P} 25$ and P25@Pd/C composite are shown in Fig. $8 \mathrm{a}$ and b, respectively. As the photoluminescence occurs due to electron-hole recombination, its intensity is directly proportional to the rate of electron-hole recombination. $\mathrm{TiO}_{2}-\mathrm{P} 25$ gave three emissions at 365, 412 and $493 \mathrm{~nm}$. The peak at $365 \mathrm{~nm}$ is ascribed to direct electron-hole recombination; the emission band
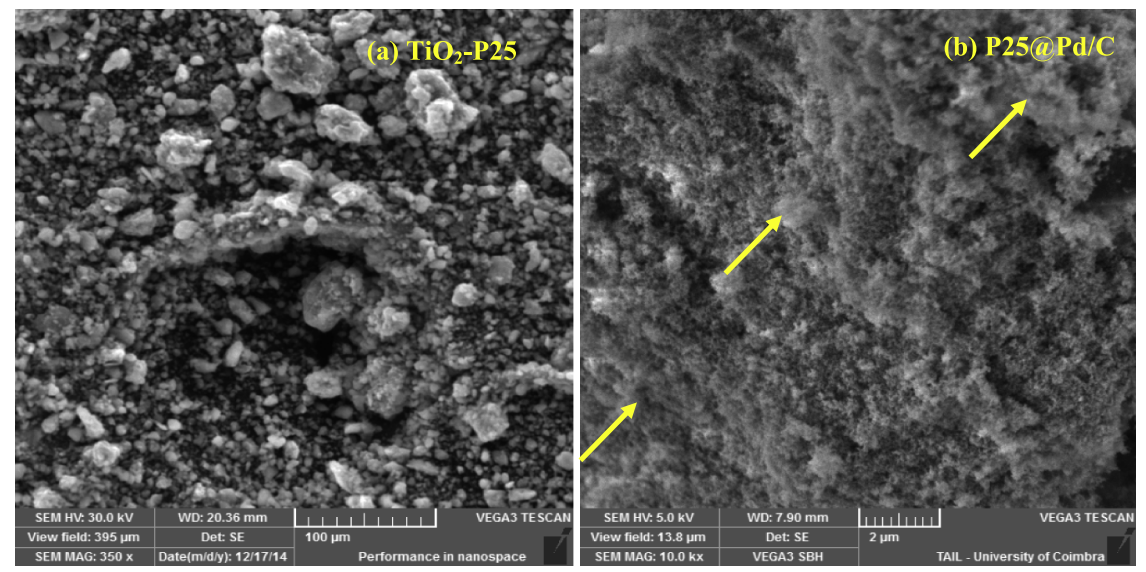

Fig. 5. SEM images of a) $\mathrm{TiO}_{2}-\mathrm{P} 25$ and b) $\mathrm{P} 25 @ \mathrm{Pd} / \mathrm{C}$. 

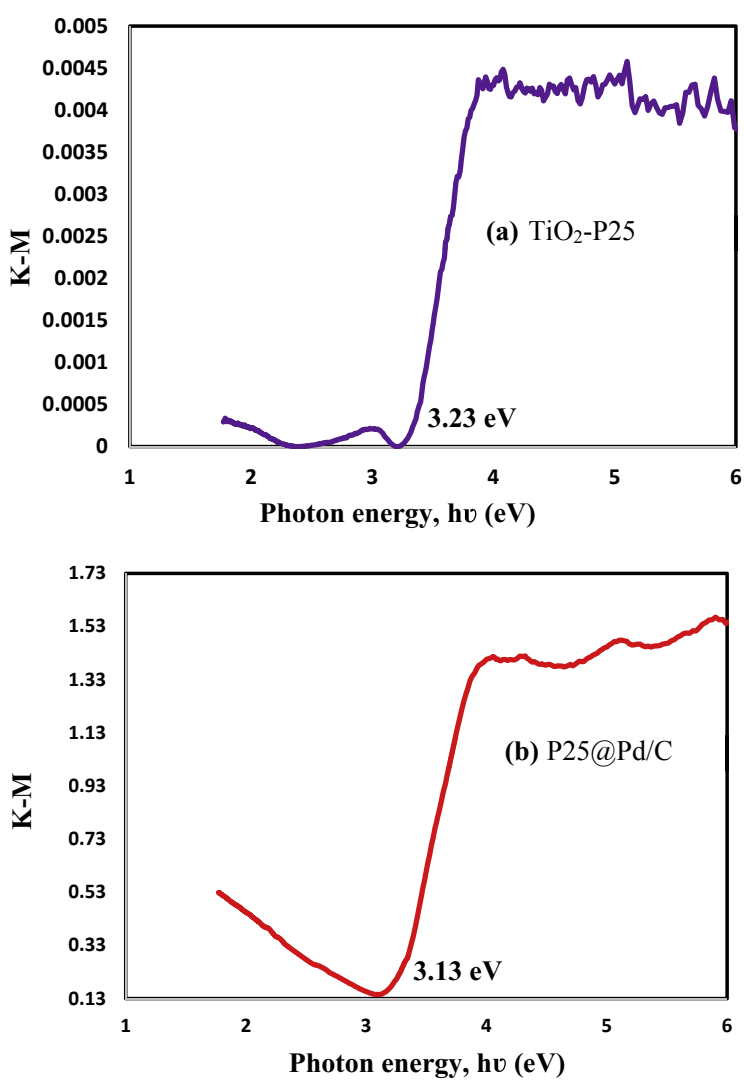

Fig. 7. K-M function for determining band gap energy of a) $\mathrm{TiO}_{2}-\mathrm{P} 25$ and b) P25@Pd/C.

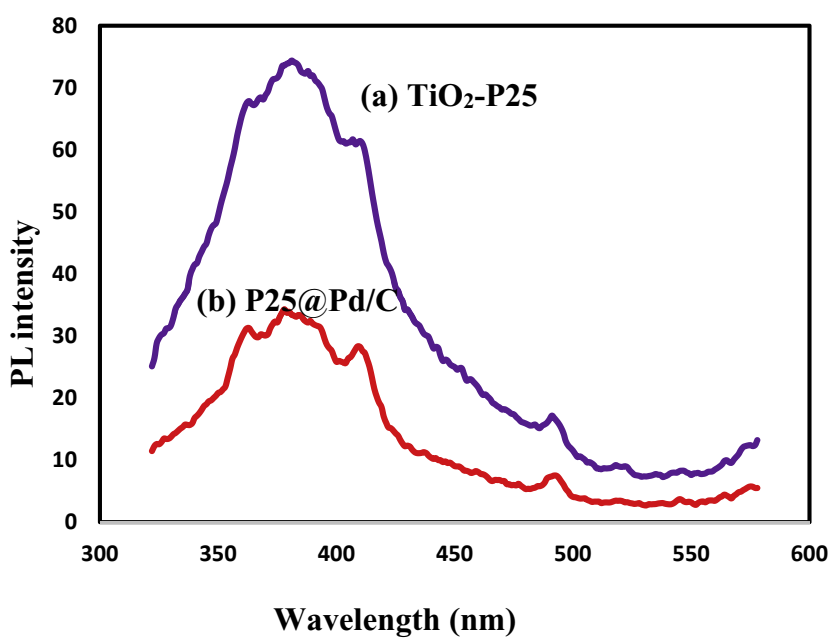

Fig. 8. Photoluminescence spectra of a) $\mathrm{TiO}_{2}-\mathrm{P} 25$ and b) P25@Pd/C.

from 400 to $500 \mathrm{~nm}$ arises from indirect band gap and surface recombination where the emission peak at $493 \mathrm{~nm}$ arises due to indirect recombination with the interaction of phonons in $\mathrm{TiO}_{2}$ lattice [25]. Modification of $\mathrm{TiO}_{2}-\mathrm{P} 25$ with $\mathrm{Pd} / \mathrm{C}$ does not shift the emission of $\mathrm{TiO}_{2}-\mathrm{P} 25$, but the intensity of PL emission is less when compared to bare $\mathrm{TiO}_{2}-\mathrm{P} 25$. This is because of suppression of recombination of electron-hole pairs by $\mathrm{Pd} / \mathrm{C}$, which enhanced the photocatalytic activity of the catalyst.

\subsection{Photodegradability}

The photocatalytic activity of the prepared P25@Pd/C was tested for the degradation of Napthol blue black (NBB) dye under visible light, activity of $\mathrm{TiO}_{2}-\mathrm{P} 25$ was also tested for comparison. The NBB azo dye, which is extensively used in dying industries, has the absorption maxima at 320 and $615 \mathrm{~nm}$. The decrease of the absorbance at $320\left(\pi \rightarrow \pi^{*}\right.$ transition $)$ and $615\left(\mathrm{n} \rightarrow \pi^{*}\right.$ transition $) \mathrm{nm}$ was used to monitor the degradation and decolourization of NBB, respectively. Photocatalytic decolourization of NBB with $\mathrm{TiO}_{2}-\mathrm{P} 25$ and P25@Pd/C catalysts under visible light is shown in Fig. 9. There is no degradation achieved when dye is irradiated without catalyst (curve a), in contrast a small decrease in dye concentration was observed (15.5\%, curve b) when dye is treated with P25@Pd/C without light. These results indicate that dye is resistant to selfphotolysis also both catalyst and light are essential for dye degradation. Under visible light irradiation at $120 \mathrm{~min}$, the dye underwent 91 (curve c) and 75.5\% (curve d) of decolourization and degradation, respectively with P25@Pd/C, whereas with $\mathrm{TiO}_{2}-\mathrm{P} 25$ only 82.6 (curve e) and 62.9\% (curve f) of decolourization and degradation observed, respectively under same condition. Since a greater loss of colour was achieved in P25@Pd/C when compared with $\mathrm{TiO}_{2}-\mathrm{P} 25, \mathrm{P} 25 @ \mathrm{Pd} / \mathrm{C}$ is found to be very efficient photocatalysts for NBB degradation under visible light. The higher activity of P25@Pd/C in visible light may be due to reduction of bandgap when compared with $\mathrm{TiO}_{2}$-P25 evidenced by DRS measurements (Figs. 6 and 7). Moreover, suppression of recombination of electron-hole pairs by Pd/C (Fig. 8), which enhanced the photocatalytic activity. The UV-vis spectra of NBB solution at different irradiation times with P25@Pd/C under visible light are shown in Fig. 10. The absorption peaks in UV and visible regions decreased gradually and finally disappeared indicating the complete degradation of the dye. There is no significant change in spectra during irradiation and the intensity at 320 and $615 \mathrm{~nm}$ decreases during the degradation. This reveals that the intermediates do not absorb at the analytical wavelengths of 320 and $615 \mathrm{~nm}$.

\subsection{Reusability}

Catalyst reusability is an important process for photocatalytic degradation process, for this reason the photocatalyst P25@Pd/C was recycled and reused. After the each degradation experiments the photocatalyst was filtered, washed with deionised water and ethanol, air dried at $110^{\circ} \mathrm{C}$ for $2 \mathrm{~h}$ and reused. The reusability of P25@Pd/C toward NBB degradation under visible light is shown in Fig. 11, which showed a drop of decolourization efficiency from $91 \%$ (first run) to $88 \%$ to fourth run. These results indicated that P25@Pd/C remain effective and reusable under visible light.

\subsection{Mechanism of photocatalytic degradation}

On the basis of the experimental results above, a mechanism for the photocatalytic degradation of NBB is suggested as follows. The higher efficiency in the degradation by P25@Pd/C than $\mathrm{TiO}_{2}-\mathrm{P} 25$ is mainly due to the synergistic effect between P25 and $\mathrm{Pd} / \mathrm{C}$ in aqueous suspension [26]. $\mathrm{TiO}_{2}-\mathrm{P} 25$ acts as a photoactive centre, carbon acts as an adsorbent and 'Pd' acts as an electron trapper (Scheme 1). When the $\mathrm{TiO}_{2}-\mathrm{P} 25$ nanoparticles modified with $\mathrm{Pd} / \mathrm{C}$ are irradiated by visible light, the $\mathrm{TiO}_{2}-\mathrm{P} 25$ excited and produced $\mathrm{e}^{-}-\mathrm{h}+$ pairs in conduction band (CB) and valence band (VB), respectively. The excited $\mathrm{CB}$ electrons are trapping by 'Pd' and they can react with the adsorbed $\mathrm{O}_{2}$ on the surface of $\mathrm{TiO}_{2}-\mathrm{P} 25$ to 


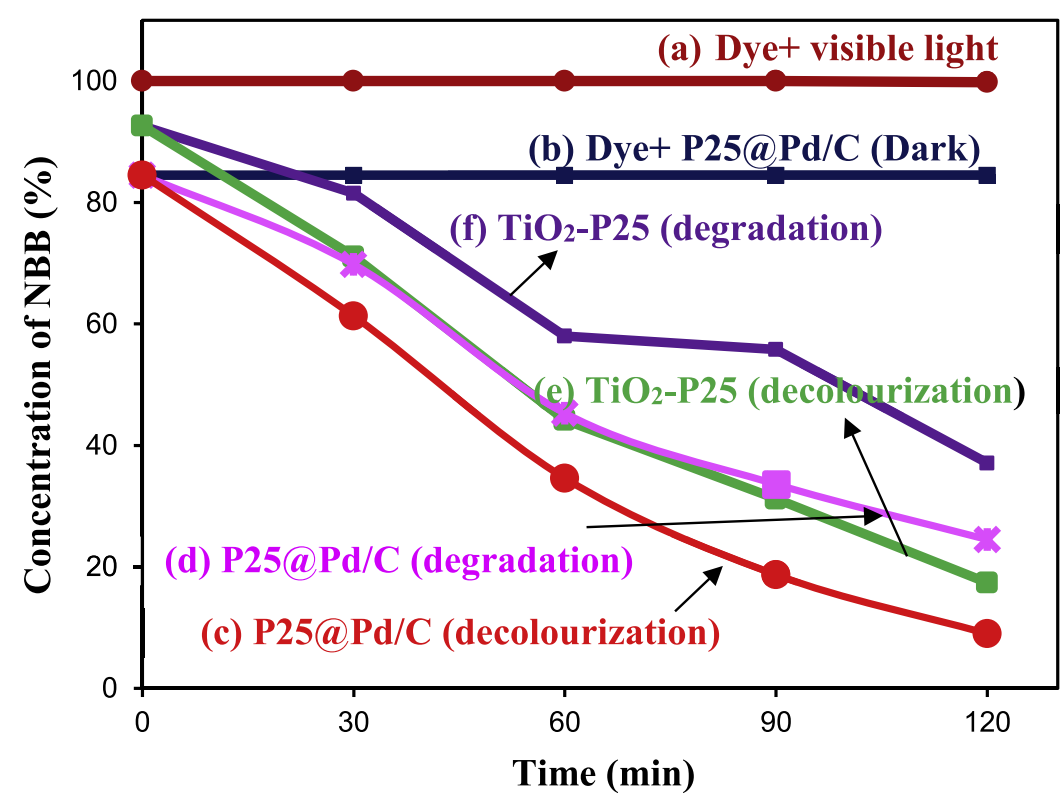

Fig. 9. Photodegradability of NBB: $[\mathrm{NBB}]=10 \mathrm{ppm}$, P25@Pd/C suspended $=10 \mathrm{mg} / 100 \mathrm{~mL}$.

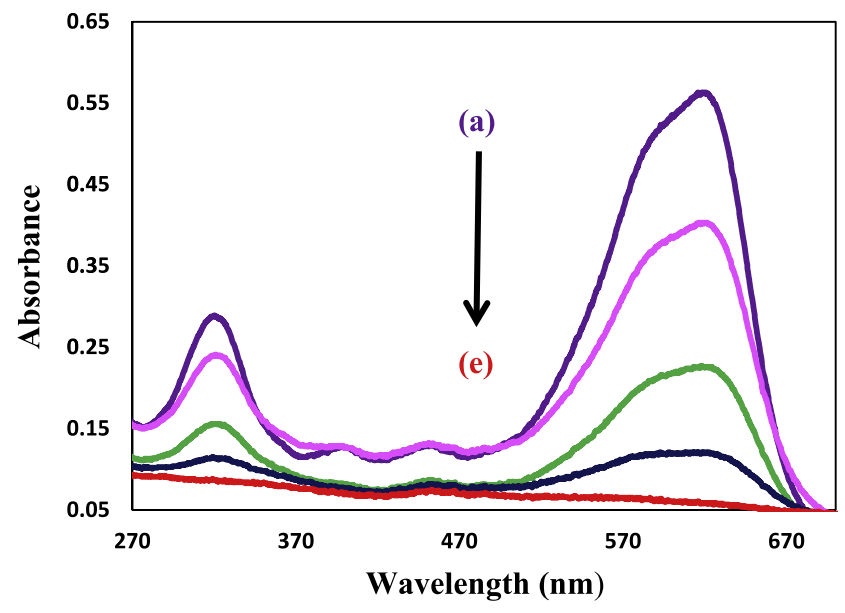

Fig. 10. UV-vis spectra of NBB on visible light irradiation in the presence of P25@Pd/C: $[\mathrm{NBB}]=10 \mathrm{ppm}, \mathrm{P} 25 @ \mathrm{Pd} / \mathrm{C}$ suspended $=10 \mathrm{mg} / 100 \mathrm{~mL}$, irradiation time $=(\mathrm{a}) 0 \mathrm{~min}$, (b) $30 \mathrm{~min}$, (c) $60 \mathrm{~min}$, (d) $90 \mathrm{~min}$ and (e) $120 \mathrm{~min}$.

produce the reactive species, such as super oxide radical anion $\left(\mathrm{O}_{2}^{\circ-}\right)$. Simultaneously, holes in the valence band $(\mathrm{VB})$ of $\mathrm{TiO}_{2}-\mathrm{P} 25$ react with water to produce hydroxyl radical $\left({ }^{\bullet} \mathrm{OH}\right)$, both species are highly reactive toward NBB degradation. Meanwhile, carbon adsorbed more numbers of dye molecules toward surface of $\mathrm{TiO}_{2}$ P25 which also enhances the dye degradation.

\section{Conclusions}

The commercially available benchmark photocatalyst Degussa P25 was modified with Pd/C and used for dye degradation under visible light. The modification was carried out simple solid state dispersion method. The prepared P25@Pd/C composite was characterized; pristine P25 was also characterized for comparison. Although no diffraction peaks of individual 'Pd' particles could be

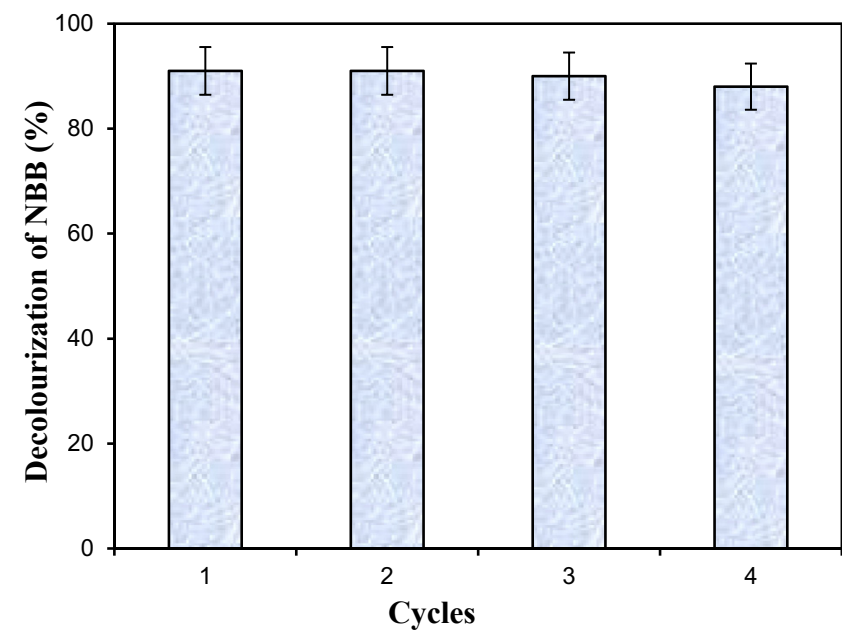

Fig. 11. Reusability of P25@Pd/C: $[\mathrm{NBB}]=10 \mathrm{ppm}, \mathrm{P} 25 @ \mathrm{Pd} / \mathrm{C}$ suspended $=10 \mathrm{mg}$ / $100 \mathrm{~mL}$, irradiation time $=120 \mathrm{~min}$.

observed in XRD of P25@Pd/C, presence of carbon confirmed by XRD measurements. Furthermore, the characteristic G-band and Dband peaks of carbon materials obviously appear in Raman spectra. P25@Pd/C has higher absorption than bare $\mathrm{TiO}_{2}-\mathrm{P} 25$ in both UV and visible region confirmed by DRS measurements and band gap energy of the P25@Pd/C is reported to be $3.13 \mathrm{eV}$. Modification of $\mathrm{TiO}_{2}-\mathrm{P} 25$ with $\mathrm{Pd} / \mathrm{C}$ does not shift the emission of $\mathrm{TiO}_{2}-\mathrm{P} 25$, but the intensity of PL emission is less when compared to bare $\mathrm{TiO}_{2}-\mathrm{P} 25$. This is because of suppression of recombination of electron-hole pairs by $\mathrm{Pd} / \mathrm{C}$, which enhanced the photocatalytic activity of the catalyst. The photocatalytic activity of the prepared P25@Pd/C composite was tested towards NBB degradation under visible light, and P25@Pd/C composite was found to be very efficient when compared with pristine P25. The catalyst was found to be reusable. 


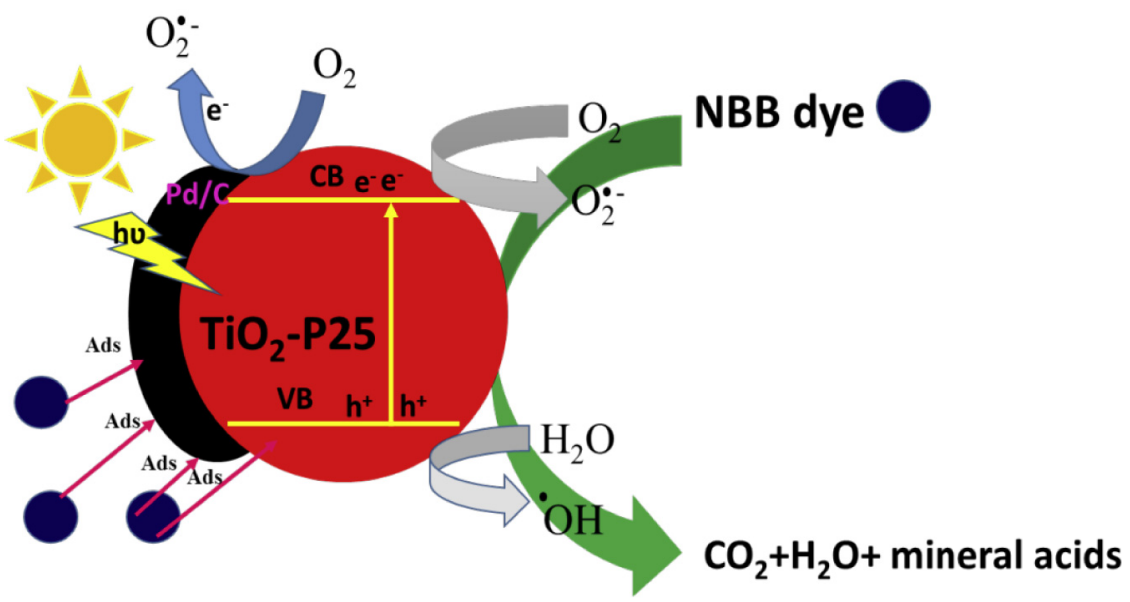

Scheme 1. Proposed mechanism of degradation of NBB by P25@Pd/C.

\section{Acknowledgments}

This work was supported by FCT postdoc-grants SFRH/BPD/ 86971/2012 (Balu Krishnakumar) SFRH/BPD/86507/2012 (SK) and ChemMat PhD program from the Fundação para a Ciência e a Tecnologia (FCT, MEC, Portugal) for their general financial support grant PD/BD/113702/2015 (António Aguiar). V. Pandiyan is highly thankful to UGC, New Delhi, Government of India through minor research project grant No. F MRP-6829/16 (SERO/UGC).

\section{References}

[1] M. Muruganandham, N. Sobana, M. Swaminathan, Solar assisted photocatalytic and photochemical degradation of Reactive Black 5, J. Hazard. Mater B137 (2006) 1371-1376.

[2] M. Muruganandham, M. Swaminathan, Photocatalytic decolourisation and degradation of reactive orange 4 by tion -uv process, Dyes Pigm 68 (2006) $133-142$.

[3] R. Velmurugan, B. Krishnakumar, Rajendra Kumar, M. Swaminathan, Solar active nano-tio 2 for mineralization of reactive red 120 and trypan blue, Arab. J. Chem. 5 (2012) 447-452.

[4] B. Krishnakumar, M. Swaminathan, Solar photocatalytic degradation of Naphthol blue black, Desalin. Water Treat. 51 (34-36) (2013) 6572-6579.

[5] B. Krishnakumar, K. Selvam, R. Velmurugan, M. Swaminathan, Influence of operational parameters on photomineralization of acid black 1 with $\mathrm{ZnO}$, Desalin. Water Treat. 24 (1-3) (2010) 132-139.

[6] B. Subash, B. Krishnakumar, M. Swaminathan, M. Shanthi, $\beta-A g 2 S-Z n O$ as a novel sunshine photocatalyst for the effective degradation of RR 120 dye, Powder Technol. 241 (2013) 49-59.

[7] G. Jiang, X. Yang, Y. Wu, Z. Li, Y. Han, X. Shen, A study of spherical $\mathrm{TiO}_{2} / g-\mathrm{C}_{3} \mathrm{~N}_{4}$ photocatalyst: morphology, chemical composition and photocatalytic performance in visible light, Mol. Catal. 432 (2017) 232-241.

[8] M. Sun, Y. Fang, Y. Kong, X. Yuan, J. Shi, A. Umar, Direct in situ synthesis of $\mathrm{Fe}_{2} \mathrm{O}_{3}$-codoped $\mathrm{N}$-doped $\mathrm{TiO}_{2}$ nanoparticles with enhanced photocatalytic and photo-electrochemical properties, J. Alloys Compd. 705 (2017) 89-97.

[9] A. Busiakiewicz, A. Kisielewska, I. Piwonski, D. Batory, The effect of Fe segregation on the photocatalytic growth of $\mathrm{Ag}$ nanoparticles on rutile $\mathrm{TiO}_{2}(001)$, Appl. Surf. Sci. 401 (2017) 378-384.

[10] S. Ragupathy, K. Raghu, P. Prabu, Synthesis and characterization of $\mathrm{TiO}_{2}$ loaded cashew nut shell activated carbon and photocatalytic activity on BG and MB dyes under sunlight radiation, Spectrochim. Acta, Part A 138 (2015) 314-320.

[11] R. Ma, X. Wang, J. Huang, J. Song, J. Zhang, X. Wang, Photocatalytic degradation of salicylic acid with magnetic activated carbon-supported F-N codoped $\mathrm{TiO}_{2}$ under visible light, Vacuum 141 (2017) 157-165.

[12] C. Wang, Z. Shi, L. Peng, W. He, B. Li, K. Li, Preparation of carbon foam-loaded nano- $\mathrm{TiO}_{2}$ photocatalyst and its degradation on methyl orange, Surf. Interfac. 7 (2017) 116-124.

13] R. Velmurugan, B. Krishnakumar, M. Swaminathan, Synthesis of Pd co-doped nano- $\mathrm{TiO}_{2}-\mathrm{SO}_{4}^{2-}$ and its synergetic effect on the solar photodegradation of Reactive Red 120 dye, Mater. Sci. Semicond. Process 25 (2014) 163-172.

[14] H. Wan, Q. Dong, G. Zhu, G. Yu, T. Yin, M. Huang, Synthesis of Pd/TiO $2-C$ composite catalysts and investigation of its performance for the electrooxidation of formic acid, Int. J. Hydrogen Energy 40 (2015) 14179-14186.

[15] Y. Li, C. Zhang, H. He, Significant enhancement in activity of $\mathrm{Pd} / \mathrm{TiO}_{2}$ catalyst for formaldehyde oxidation by Na addition, Catal. Today 281 (2017) 412-417.

[16] R. Liu, H. Li, L. Duan, H. Shen, Y. Zhang, X. Zhao, In situ synthesis and enhanced visible light photocatalytic activity of $\mathrm{C}-\mathrm{TiO}_{2}$ microspheres/carbon quantum dots, Ceram. Int. 43 (2017) 8648-8654.

17] X. Wei, H. Wang, X. Wang, W. Jiang, Facile synthesis of tunable carbon modified mesoporous $\mathrm{TiO}_{2}$ for visible light photocatalytic application, Appl. Surf. Sci. 412 (2017) 357-365.

[18] Z.C. Kadirova, M. Hojamberdiev, K. Katsumata, T. Isobe, N. Matsushita, A. Nakajima, K. Okada, $\mathrm{Fe}_{2} \mathrm{O}_{3}$-loaded activated carbon fiber/polymer materials and their photocatalytic activity for methylene blue mineralization by combined heterogeneous-homogeneous photocatalytic processes, Appl. Surf. Sci. 402 (2017) 444-455.

[19] L.A. Estudillo-Wong, A.M. Vargas-Gómez, E.M. Arce-Estrada, A. ManzoRobledo, $\mathrm{TiO}_{2} / \mathrm{C}$ composite as a support for Pd-nanoparticles toward the electrocatalytic oxidation of methanol in alkaline media, Electrochim. Acta 112 (2013) 164-170.

[20] N. Sobana, B. Krishnakumar, M. Swaminathan, Synergism and effect of operational parameters on solar photocatalytic degradation of Direct Yellow 4 with AC-ZnO, Mater. Sci. Semicond. Process 16 (2013) 1046-1051.

[21] N. Sobana, M. Swaminathan, Combination effect of $\mathrm{ZnO}$ and activated carbon for solar assisted photocatalytic degradation of Direct Blue 53, Sol. Energy Mater. Sol. Cells 91 (2007) 727-734.

[22] B. Chen, N. Zhao, C. Wei, J. Zhou, F. He, C. Shi, C. He, E. Liu, Multi-functional integration of pore P25@C@MoS2 core-double shell nanostructures as robust ternary anodes with enhanced lithium storage properties, Appl. Surf. Sci. 401 (2017) 232-240.

[23] M. Li, B. Lu, Q. Ke, Y. Guo, Y. Guo, Synergetic effect between adsorption and photodegradation on nanostructured $\mathrm{TiO}_{2} /$ activated carbon fiber felt porous composites for toluene removal, J. Hazard. Mater. 333 (2017) 88-98.

[24] B. Krishnakumar, A. Balakrishna, C.T. Arranja, C.M.F. Dias, Abilio J.F.N. Sobral, Chemically modified amino porphyrin/ $/ \mathrm{TiO}_{2}$ for the degradation of Acid Black 1 under day light illumination, Spectrochim. Acta, Part A 176 (2017) 134-141.

[25] B. Liu, X. Zhao, O. Zhao, X. He, J. Feng, Effect of heat treatment on the UV-vis-NIR and PL spectra of $\mathrm{TiO}_{2}$ films, J. Electron. Spectrosc. Relat. Phenom. 148 (2005) 158-163.

[26] N. Sobana, M. Muruganandam, M. Swaminathan, Characterization of AC-ZnO catalyst and its photocatalytic activity on 4-acetylphenol degradation, Catal. Commun. 9 (2008) 262-268. 